Reprod. Nutr. Dévelop., 1984, 24 (5 B), 780. - Assoc. Fr. Nutr., oct. 1983.

\title{
Etude des vitesses de synthèse et des " turn over " d'enzymes pancréatiques chez le rat en croissance sous l'effet d'une malnutrition protéinocalorique (MPE) suivie d'une réalimen- tation équilibrée (RE), par Carole VALANTIN, Josiane PROST, J. BELLEVILLE. Laboratoire de physiologie animale et Nutrition, B.P. 13821004 Dijon Cedex, France.
}

Des études antérieures ont montré que les activités enzymatiques digestives sont perturbées par la malnutrition protéique et que la réhabilitation nutritionnelle ne donnait pas toujours les résultats escomptés. Nous avons également montré la nécessité de réaliser des études chronologiques puisque les modifications ne se produisent pas toujours de façon régulière. Afin de déterminer où se produisent les perturbations, nous nous proposons de vérifier à quels niveaux se situent la dissociation entre activités dans le pancréas (EP) et celle du suc pancréatique (SP). Pour cela, il nous a paru nécessaire d'étudier les vitesses de synthèse et d'excrétion de certaines enzymes digestives pancréatiques.

Méthodes. -100 rats mâles Wistar de $120 \mathrm{~g}$ sont répartis en 2 lots. Le lot témoin (T) qui reçoit un régime contenant $20 \%$ de protéines ( 4 parts de gluten, 1 part de caséine) pendant 51 jours et le lot expérimental $(E)$ qui reçoit un régime à $5 \%$ de protéines pendant 28 jours (MPE), puis le régime T pendant 23 jours (RE). Aux jours 2. 9. 16. 23 de MPE et 2. 9. 23 de $\mathrm{RE}$, on réalise une fistule pancréato-biliaire sur 6 rats de chaque lot. Deux heures après intubation de leur régime respectif, on injecte $100 \mu$ Cie de leu $3 \mathrm{H}$ par I.V. $\left(\mathrm{t}_{0}\right)$. Chez 3 rats, le SP est collecté à t 20-40-60-90-120-150-180-240 min et sur les 3 autres rats à $t$ $40 \mathrm{~min}, \mathrm{SP}$ et EP sont prélevés. On évalue la RAS (dpm/ $\mathrm{mg}$ de protéine) de la trypsine, chymotrypsine, lipase et $\alpha$ amylase dans les SP et les EP après traitement de chaque échantillon par IEF (séparation des protéines enzymes selon leur PI) et évaluation de la radioactivité de chacune des enzymes étudiées par scintillation liquide.

Résultats. - Dans le SP, le pic de radioactivité lié aux protéines apparaît entre 20 et $60 \mathrm{~min}$. Au $2^{2}$ jour de MPE, les rats $E$ présentent une RAS supérieure à celle des T reflétant l'accélération du renouvellement des protéines enzymes. Cette différence entre les 2 lots s'atténue progressivement au cours du temps. Pendant les 2 premières semaines de $\mathrm{RE}$, la synthèse est défavorisée puis privilégiée au $23^{e}$ jour. Parallèlement, les contenus des EP sont peu affectés.

L'amylase est la plus affectée. Sa vitesse de synthèse diminue fortement au début de MPE puis se rétablit à un niveau voisin de $T$.

La vitesse de synthèse de la trypsine subit des modifications avec diminution au $2^{\mathrm{e}}$ jour de MPE puis forte augmentation en début de RE.

La vitesse de synthèse de la chymotrypsine est peu affectée et celle de la lipase diminue au $9^{e}$ jour de MPE.

Conclusion. - Les synthèses des quatre enzymes étudiées sont modifiées d'une façon différentielle par la PME et la RE.

Prost J., Belleville J., Bouziane M., 1982, 1983. Etude comparée des effets de 2 types de malnutrition protéino-énergétiques suivies d'une réalimentation équilibrée : 1) Sur les activités trypsique et chymotrypsique du pancréas et du suc pancréatique de rat ; 2) Sur les activités lipasique, phospholipasique $A_{2}$ et amylasique du pancréas et du suc pancréatique chez le rat en croissance. 1. C.R. Soc. Biol., 176, 1982, 690-694. 2. C.R. Soc. Biol., 177, 1983, 488. 